\title{
Research on Supply Chain Decision Making Based on the Shortage of Market Supply
}

\author{
Heng LIU \\ School of Economics and Management \\ HUIZHOU University \\ Huizhou, China \\ e-mail: Liuheng73@163.com
}

\begin{abstract}
This paper studies the optimal decision of retailer and supplier based on the shortage of market supply. Compared with the normal supply situation, it is found less optimal order quantity from the retailer; and that the retailer's optimal order quantity decreases with the increasing of wholesale prices, increases with the increasing of the retail price and residual value. The supplier can increase the order quantity of the retailer through the buyback contract, but cannot coordinate the supply chain through the buyback contract.
\end{abstract}

\section{Keywords-component; disruption; shortage; buyback contract}

\section{INTRODUCTION}

It is often encountered in the case of goods out of stock in life, that is, consumers cannot find the goods on the shelf catalog of goods, which will bring losses to retailers. There are two reasons for the emergence of the shortage, the normal operation of enterprise or disruption, such as natural disasters.

In the normal operation management of the enterprise, retailers generally take appropriate adjustments to the inventory level or through the con-tract with suppliers to optimize supply chain to solve the problem of shortage. The retailer adjusts the inventory level by using EOQ model to control the rate of shortage of goods under the normal sup-ply situation [1] [2]. When the retailer sign the contract with the supplier, first of all, it is assumed that there is a delay in delivery, and delay then cause the sales out of stock and sales loss [3-6]. In order to solve the delay of delivery, the retailer should punish the supplier, or receive allowance from the supplier. Anderson (2006) analysis of the stock loss of the short-term orders and long-term orders respectively [7]. Liu Bin, Cui Wentian (2009) studied supply chain coordination for perishable product when the stock loss is higher than the replenishment cost [8]. On the basis of risk-neutral decision-makers, scholars furtherly consider how decision-makers is influenced by the different risk-preference types in supply chain. The risk construction using in financial theory, such as Mean Variance Tradeoff [9], the Value at Risk [10], the Conditional Value at Risk (CVaR) [11], Prospect Theory [12], Utility Function, is characterized in supply chain. For example, it has been pointed out that without considering the loss of sales situation, the order quantity of a risk-averse retailer is less than that of the risk-neutral retailer; but with the loss of sales and under certain conditions, the optimal order quantity of a risk-averse retailer may be greater than that of a risk-neutral retailer [12]. In order to achieve the overall optimization of a supply chain, scholars put forward the different contract design, such as repurchase, revenue sharing, minimum order quantity, etc. based on symmetric information and asymmetric information [13] [14].

When the disruption occurred in supply chain [15], scholars have done in-depth research on optimal decision, assumed that natural disasters or disruption change the supply-demand relationship [16] [17], and compared the optimal decision with that under normal management, point out realized coordination in the supply chain [18-21].

These above studies have a same hypothesis that the supplier would adequate supply to retailers for sales after the order made, even if the supplier lacking of funds can also ensure that the procurement of raw materials to meet the order through loans.

However, there are some situation that suppliers would be unable to fully supply to retailer due to shortage of raw materials in real life, and that will also lead retailers out of stock. In this case, contract parameters cannot be adjusted to solve the shortage rate or to coordinate the supply chain.

Unlike the previous two different ways to look at the shortage of goods, if the decision-makers recognize that there will be a shortage supply in the future, they will need to make decisions on the basis of shortage supply. For example, after South Korea's Samsung made Note7 mobile phone rec-all after the explosion at the end of September 2016, Samsung Corp raise the prices of the phone display screen and memory accessories to compensate for the loss by using its monopoly situation in mobile phone accessories, and made a new limited supply quantity for the Chinese mobile phone manufacturers due to the capacity gaps existing at the same time (but the Apple Corp and Samsung mobile phone both have the priority to meet the order). The shortage is expected to continue for 2 years. As for Chinese mobile phone manufacturers, there is something must be done: competition for deals; because of budget constraints, it is unable to buy enough mobile phone accessories production; instability of Samsung supply; retail prices of mo-bile phone cannot lift up due to market oversupply of mobile phone. 
Therefore, it is assumed that the retailer orders with full payment to the supplier, but the supplier may not provide the full amount of goods according to order at the end of the delivery period, so the retailers can only be sold according to the actual supply. By constructing the Stackelberg game decision function between suppliers and retailers, this paper studies the optimal decision and the factors that influence the optimal decision. First of all, the paper studies the optimal decisions under the wholesale price contract, and then studies whether the supply chain can be coordinated.

\section{Model AsSumption}

A supply chain is considered consisting of a single supplier and a single retailer in a sales cycle. The supplier is leader making the wholesale price $w$ to the retailer firstly. The retailer is the follower, determining the order quantity $Q$ according to the retail price $p$ and the wholesale price $w$, and paying the full payment to the supplier ${ }^{1}$. The sup-plier purchases the raw material with the unit cost $c$. But due to unpredict events, such as earthquakes, floods and other natural disasters, supplier provide the only part of product $q$ to retailers before the sales season beginning, nor the amount owed to the retailer compensation. $q$ is subject to uniform distribution, $q \in[0, Q]$, and distribution density function $s(q)$, and distribution function is $S(q)$, and be the common acknowledge of retailers and suppliers. Retailers still sell their products at sale price $p$ during the sales season ${ }^{2}$.

The market random demand is $x$ with the density function bounded $f(x)$, and distribution function $F(x)$, $x \in(0,+\infty)$. Unit unsold sales after the sales season has the residual value of $v$.

Superscript - is identified the business decisions when the supply does not exist shortage, superscript $*$ be the optimized business decisions, subscript sym be the centralized decision-making, subscript $\mathrm{r}$ be the retailers, subscript $\mathrm{s}$ be the supliers.

\section{Optimal Decision of Centralized Situation}

The centralized supply chain (or integrated supply chain) means that the supplier and the retailer belong to a virtual organization, and the same manager makes the decision to maximize the profit of the supply chain system. The virtual organization only needs to determine the optimal quantity production.

The sales revenue is

$$
\prod \text { sym }=\left\{\begin{array}{r}
p x+v(q-x), q \leq x \\
p q, q>x
\end{array}\right.
$$

\footnotetext{
1 Another possibility is that the retailer pays the money to the supplier according to the actual quantity, and the amount is different.

${ }^{2}$ It is possible for retailers to sell at the original retail price. On the one hand, they may come from the government's price control in a certain period of time. On the other hand, there are alternatives to price competition.
}

Expected profit is

$$
\begin{gathered}
\pi_{s y m}=\int_{0}^{Q}\left(p \int_{0}^{q} x f(x) d x+v \int_{0}^{q}(q-x) f(x) d x+\right. \\
\left.p q \int_{q}^{+\infty} f(x) d x\right) s(q) d q-c \int_{0}^{Q} q s(q) d q= \\
\int_{0}^{Q}\left(p \int_{0}^{q} x f(x) d x+v \int_{0}^{q}(q-x) f(x) d x+\right. \\
\left.p q \int_{q}^{+\infty} f(x) d x\right) s(q) d q-\frac{c}{2} Q
\end{gathered}
$$

We get the first derivative of $\pi_{\text {sym }}$ about $Q$ as

$$
\frac{\partial \pi_{s y m}}{\partial Q}=p-\frac{c}{2}-(p-v) \frac{\int_{0}^{Q} F(x) d x}{Q}
$$

We have

$$
\begin{gathered}
\lim _{Q \rightarrow 0^{+}}\left(p-(p-v) \frac{\int_{0}^{Q} F(x) d x}{Q}-\frac{c}{2}\right)=p-\frac{c}{2}>0 \\
\lim _{Q \rightarrow+\infty}\left(p-(p-v) \frac{\int_{0}^{Q} F(x) d x}{Q}-\frac{c}{2}\right)=v-\frac{c}{2}<0
\end{gathered}
$$

We get the second derivative of $\pi_{\text {sym }}$ about $Q$ as

$$
\frac{\partial^{2} \pi_{s y m}}{\partial Q^{2}}=-(p-v) \frac{F(Q) Q-\int_{0}^{Q} F(x) d x}{Q^{2}}<0
$$

$\frac{\partial^{2} \pi_{s y m}}{\partial Q^{2}}<0$ means the existence of a $Q$ max-imize $\pi_{\text {sym }}$.

we denote the order quantity $Q_{s y m}^{*}$ meet $\frac{\partial \pi_{s y m}}{\partial Q}=0$. That is

$$
\frac{\int_{0}^{Q_{s y m}^{*}} F(x) d x}{Q_{s y m}^{*}}=\frac{2 p-c}{2(p-v)}
$$

Corollary 1 Under the centralized situation, production quantity when the supply exist supply shortage is greater than that without supply shortage.

Proof: when supply is without shortage, supplier can always purchase the sufficient raw material from the market.

The sales revenue is as formula (1).

Expected profit is

$$
\begin{aligned}
& \overline{\pi_{\text {sym }}}=p \int_{0}^{Q} x f(x) d x+v \int_{0}^{Q}(Q-x) f(x) d x \\
& +p q \int_{Q}^{+\infty} f(x) d x-c Q
\end{aligned}
$$

It is easy to get the optimal production quantity $F\left(\overline{Q_{s y m}^{*}}\right)=\frac{p-c}{p-v}$. If $Q_{s y m}^{*} \leq \overline{Q_{s y m}^{*}}$ then $\int_{0}^{Q_{s y m}^{*}} F(x) \mathrm{d} x<$ $Q_{s y m}^{*} F\left(Q_{s y m}^{*}\right)<Q_{s y m}^{*} F\left(\overline{Q_{s y m}^{*}}\right)$, which is obviously not exist.

So, there will be $Q_{s y m}^{*}>\overline{Q_{s y m}^{*}}$.

Corollary 1 can also be understood from the daily life. When the expected supply is in shortage, the general 
reflection of the enterprise will increase production (or order).

\section{THE RETAILER'S OPTIMAL DECISION-MAKING UNDER DECENTRALIZED SUPPLY CHAIN}

Under decentralized supply chain, there is a Stackelberg game between retailer and supplier which is leader. The inverse method is used to analyze the Stackelberg game.

The retailer's sales revenue is

$$
\Pi r=\left\{\begin{array}{c}
p x+v(q-x), q \leq x \\
p q, q>x
\end{array}\right.
$$

The retailer's expected profit is

$$
\begin{aligned}
& \pi_{r}=\int_{0}^{Q}\left(p \int_{0}^{q} x f(x) d x+v \int_{0}^{q}(q-x) f(x) d x+\right. \\
& \left.p q \int_{q}^{+\infty} f(x) d x\right) s(q) d q-w Q
\end{aligned}
$$

We get the first derivative of $\pi_{r}$ about $Q$ as

$$
\frac{\partial \pi_{r}}{\partial Q}=p-w-(p-v) \frac{\int_{0}^{Q} F(x) d x}{Q}
$$

We have

$$
\begin{aligned}
& \lim _{Q \rightarrow 0^{+}}\left(p-w-(p-v) \frac{\int_{0}^{Q} F(x) d x}{Q}\right)=p-w>0 \\
& \lim _{Q \rightarrow+\infty}\left(p-w-(p-v) \frac{\int_{0}^{Q} F(x) d x}{Q}\right)=v-w<0 \\
& \text { We get the second derivative of } \pi_{r} \text { about } Q \text { as }
\end{aligned}
$$

$$
\frac{\partial^{2} \pi_{r}}{\partial Q^{2}}=-(p-v) \frac{F(Q) Q-\int_{0}^{Q} F(x) d x}{Q^{2}}<0
$$

$\frac{\partial^{2} \pi_{r}}{\partial Q^{2}}<0$ means the existence of a $Q$ maximize $\pi_{r}$.

We denote the order quantity $Q^{*}$ to meet $\frac{\partial \pi_{r}}{\partial Q}=0$

$$
\frac{\int_{0}^{Q^{*}} F(x) d x}{Q^{*}}=\frac{p-w}{p-v}
$$

We denote $\Delta=\frac{\partial\left(\frac{\int_{0}^{Q^{*}} F(x) \mathrm{d} x}{Q^{*}}\right)}{\partial Q^{*}}=\frac{F\left(Q^{*}\right) Q^{*}-\int_{0}^{Q^{*}} F(x) \mathrm{d} x}{\left(Q^{*}\right)^{2}}(>0)$.

Corollary 2 When the supply is in shortage, the optimal-order quantity of retailer is greater than that without supply shortage.

Proof: The retailer's expected profit without supply shortage is

$$
\pi_{r}=p \int_{0}^{Q} x f(x) d x+v \int_{0}^{Q}(q-x) f(x) d x+p q \int_{Q}^{+\infty} f(x) d x
$$

The optimal order quantity $\overline{Q^{*}}$ of the retailer without supply shortage is satisfied

$$
F\left(\overline{Q^{*}}\right)=\frac{p-w}{p-v}
$$

Combined with formula (10), we have

$$
\frac{\int_{0}^{Q^{*}} F(x) d x}{Q^{*}}=F\left(\overline{Q^{*}}\right)
$$

and

$$
\begin{gathered}
\frac{\int_{0}^{Q^{*}} F(x) d x}{Q^{*}}=F\left(\overline{Q^{*}}\right)<\frac{\int_{0}^{Q^{*}} F\left(Q^{*}\right) d x}{Q^{*}}=\frac{F\left(Q^{*}\right) \int_{0}^{Q^{*}} d x}{Q^{*}} \\
=\frac{F\left(Q^{*}\right) Q^{*}}{Q^{*}}=F\left(Q^{*}\right)
\end{gathered}
$$

Corollary 2 can also be understood from the daily life. When the expected supply is in shortage, the general reflection of the enterprise will increase production (or order).

Corollary 3 The optimal-order quantity of retailers under decentralized decision is less than that under centralized decision.

Proof: We denote $G(Q)=\frac{\int_{0}^{Q} F(x) \mathrm{d} x}{Q}$ and has the first derivative of $G(Q)$ for $Q$

$$
\frac{\partial G(Q)}{\partial Q}=\frac{F(Q) Q-\int_{0}^{Q} F(x) d x}{Q^{2}}>0
$$

$\frac{F(Q) Q-\int_{0}^{Q} F(x) \mathrm{d} x}{Q^{2}}>0$ means $G(Q)$ is an increasing function of $Q$.

Because

$\frac{\int_{0}^{Q^{*}} F(x) d x}{Q^{*}}=\frac{p-w}{p-v}=\frac{2 p-2 w}{2(p-v)}<\frac{2 p-c}{2(p-v)}=\frac{\int_{0}^{Q_{s y m}^{*}} F(x) d x}{Q_{s y m}^{*}}$

So, we have $Q^{*}<Q_{\text {sym }}^{*}$.

Corollary 4 The optimal quantity order of retailer's decreases with the wholesale price increasing, and increase with the retail price and value increasing.

Proof: we have $Q^{*}$ the first derivative for $w, p$ and $v$ as follow

$$
\begin{gathered}
\frac{\partial \mathrm{Q}^{*}}{\partial \mathrm{w}}=-\frac{1}{(\mathrm{p}-\mathrm{v}) \Delta}<0 \\
\frac{\partial \mathrm{Q}^{*}}{\partial \mathrm{v}}=\frac{\int_{0}^{\mathrm{Q}^{*}} \mathrm{~F}(\mathrm{x}) \mathrm{dx}}{(\mathrm{p}-\mathrm{v}) \Delta \mathrm{Q}^{*}}>0 \\
\frac{\partial \mathrm{Q}^{*}}{\partial \mathrm{p}}=\frac{\mathrm{Q}^{*}-\int_{0}^{\mathrm{Q}^{*}} \mathrm{~F}(\mathrm{x}) \mathrm{dx}}{(\mathrm{p}-\mathrm{v}) \Delta \mathrm{Q}^{*}}>0
\end{gathered}
$$

\section{The Optimal Whole Sale Price of Supplier UNDER DECENTRALIZED SUPPLY CHAIN}

After the retailer paid all the money in advance to the supplier with the order, the supplier arrange the purchase of raw materials. The supplier's expected profit is

$$
\pi_{s}=w Q^{*}-c \int_{0}^{Q^{*}} q s(q) d q=w Q^{*}-\frac{c Q^{*}}{2}
$$

Corollary 5 The supplier has optimal wholesale price.

Proof: we have the first derivative of $\pi_{s}$ for $w$ and get

$$
\frac{\partial \pi_{s}}{\partial w}=Q^{*}+w \frac{\partial Q^{*}}{\partial w}-\frac{c}{2} \frac{\partial Q^{*}}{\partial w}=Q^{*}+\left(w-\frac{c}{2}\right) \frac{\partial Q^{*}}{\partial w}
$$


Because of $w>c>\frac{c}{2}, \frac{\partial Q^{*}}{\partial w}=-\frac{1}{(p-v) \Delta}<0$, so there is a wholesale price satisfied $\frac{\partial \pi_{s}}{\partial w}=0$.

When $Q \rightarrow 0^{+}$, there is

$$
\begin{aligned}
& \lim _{\mathrm{Q} \rightarrow 0^{+}}\left(\mathrm{Q}^{*}+\left(\mathrm{w}-\frac{\mathrm{c}}{2}\right) \frac{\partial \mathrm{Q}^{*}}{\partial \mathrm{w}}\right) \\
& =-\frac{\mathrm{w}-\frac{\mathrm{c}}{2}}{\mathrm{p}-\mathrm{v}} \lim _{\mathrm{Q} \rightarrow 0^{+}} \frac{\left(\mathrm{Q}^{*}\right)^{2}}{\mathrm{~F}\left(\mathrm{Q}^{*}\right) \mathrm{Q}^{*}-\int_{0}^{\mathrm{Q}^{*}} \mathrm{~F}(\mathrm{x}) \mathrm{dx}} \\
& =-\frac{\mathrm{w}-\frac{\mathrm{c}}{2}}{\mathrm{p}-\mathrm{v}} \lim _{\mathrm{Q} \rightarrow 0^{+}} \frac{2 \mathrm{Q}^{*}}{\mathrm{f}\left(\mathrm{Q}^{*}\right) \mathrm{Q}^{*}+\mathrm{F}\left(\mathrm{Q}^{*}\right)-\mathrm{F}\left(\mathrm{Q}^{*}\right)} \\
& =-\frac{\mathrm{w}-\frac{\mathrm{c}}{2}}{\mathrm{p}-\mathrm{v}} \lim _{\mathrm{Q} \rightarrow 0^{+}} \frac{2 \mathrm{Q}^{*}}{\mathrm{f}\left(\mathrm{Q}^{*}\right) \mathrm{Q}^{*}}<0
\end{aligned}
$$

When $Q \rightarrow+\infty$, there is

$$
\begin{array}{r}
\lim _{\mathrm{Q} \rightarrow+\infty}\left(\mathrm{Q}^{*}+\left(\mathrm{w}-\frac{\mathrm{c}}{2}\right) \frac{\partial \mathrm{Q}^{*}}{\partial \mathrm{w}}\right) \\
=\lim _{\mathrm{Q} \rightarrow+\infty}\left(\mathrm{Q}^{*}\right. \\
\left.-\left(\mathrm{w}-\frac{\mathrm{c}}{2}\right) \lim _{\mathrm{Q} \rightarrow+\infty} \frac{\left(\mathrm{Q}^{*}\right)^{2}}{\mathrm{~F}\left(\mathrm{Q}^{*}\right) \mathrm{Q}^{*}-\int_{0}^{\mathrm{Q}^{*}} \mathrm{~F}(\mathrm{x}) \mathrm{dx}}\right) \\
=\lim _{\mathrm{Q} \rightarrow+\infty}\left(\mathrm{Q}^{*}-\left(\mathrm{w}-\frac{\mathrm{c}}{2}\right) \lim _{\mathrm{Q} \rightarrow+\infty} \frac{2 \mathrm{Q}^{*}}{\mathrm{f}\left(\mathrm{Q}^{*}\right) \mathrm{Q}^{*}+\mathrm{F}\left(\mathrm{Q}^{*}\right)-\mathrm{F}\left(\mathrm{Q}^{*}\right)}\right) \\
=\lim _{\mathrm{Q} \rightarrow+\infty}\left(\mathrm{Q}^{*}-\left(\mathrm{w}-\frac{\mathrm{c}}{2}\right) \lim _{\mathrm{Q} \rightarrow+\infty} \frac{2 \mathrm{Q}^{*}}{\mathrm{f}\left(\mathrm{Q}^{*}\right) \mathrm{Q}^{*}}\right) \\
=\lim _{\mathrm{Q} \rightarrow+\infty}\left(\mathrm{Q}^{*}-\left(\mathrm{w}-\frac{\mathrm{c}}{2}\right) \lim _{\mathrm{Q} \rightarrow+\infty} \frac{2}{\mathrm{f}\left(\mathrm{Q}^{*}\right)}\right) \rightarrow+\infty
\end{array}
$$

There must be a wholesale price $w^{*}=\frac{c}{2}-Q^{*} \frac{\partial w}{\partial Q^{*}}>0$, existing to maximize the supplier's expected profit.

\section{BUYBACK CONTRACT ANALYSIS}

By corollary 3 it is knowing that the retailer's optimal order quantity under decentralized decision is less than that under centralized decision, so whether the buyback contract that can coordination supply chain without shortage supply can achieve the same effect on supply chain with shortage supply? There is corollary 6.

Corollary 6 The buyback contract cannot coordinate the supply chain, but can increase the order quantity of the retailer.

Proof: we proof by contradiction.

If the supplier promise at the price $(w, b)$ which $b$ is the recycling price for the unsold products in retailer, then the retailer does not deal with the goods after the sale season.

$$
\frac{\int_{0}^{Q_{b}^{*}} F(x) d x}{Q^{*}}=\frac{p-w}{p-b}
$$

We substitute $b$ for $v$ in the formula (10), and have the retailer's optimal order quantity und-er buyback contract to meet.

Make $Q^{*}=Q_{s y m}^{*}$. Form formula (5) and (12), we get

$$
\mathrm{b}=\frac{2(\mathrm{p}-\mathrm{v})}{2 \mathrm{p}-\mathrm{c}} \mathrm{w}-\frac{\mathrm{c}-2 \mathrm{v}}{2 \mathrm{p}-\mathrm{c}} \mathrm{p}
$$

Firstly, we discuss the scope of the recycling price $b$.

If $v=b$, then from $\frac{\int_{0}^{Q_{s y m}^{*}} F(x) \mathrm{d} x}{Q_{s y m}^{*}}=\frac{\int_{0}^{Q_{b}^{*}} F(x) \mathrm{d} x}{Q^{*}}$, we have $w=\frac{c}{2}<c$, but this is obviously impossible. If $v>b$, the retailer will deal with the goods and not hand the goods over to suppliers. So, there must be $v<b$.

Because $w>b \geq 0$, we get formula (14) from formula (13).

$$
w \geq \frac{p(c-2 v)}{2(p-v)}
$$

Formula (14) showed that the necessary cond-ition for suppliers to fulfil buyback contract is $c>2 v$ and $w \geq \frac{p(c-2 v)}{2(p-v)}$.

Then we discuss the trend of recycling price.

We denote $M_{1}=\frac{2(p-v)}{2 p-c}, M_{2}=\frac{c-2 v}{2 p-c}$, and re-write the recycling price as

$$
b=M_{1} w-M_{2} p
$$

From $\frac{\partial b}{\partial w}=M_{1}>0$, it is knowing that the recycling price increases with the wholesale price increasing.

$\frac{\frac{\partial b}{b}}{\frac{\partial w}{w}}=\frac{\partial b}{\partial w} \frac{w}{b}>1$ shows that the recycling price increase more than the wholesale price increase, which means the retailer's order quantity increases with the recycling price increasing when the wholesale price is fixed.

Because

$$
\begin{gathered}
\lim _{w \rightarrow\left(\frac{p(c-2 v)}{2(p-v)}\right)^{+}} b=\frac{2(p-v)}{2 p-c} \frac{p(c-2 v)}{2(p-v)}-\frac{c-2 v}{2 p-c} p \\
=\frac{p(c-2 v)}{2 p-c}-\frac{c-2 v}{2 p-c} p=0 \\
\lim _{w \rightarrow p^{-}} b=\frac{2(p-v)}{2 p-c} p-\frac{c-2 v}{2 p-c} p=\left(\frac{2 p-c}{2 p-c}\right) p=p \\
\text { We denote } H(w)=\frac{p-w}{p-b}, \text { then we have } \\
\lim _{w \rightarrow p^{-}} H(w)=\lim _{w \rightarrow p^{-}} \frac{p-w}{\left(1+M_{2}\right) p-M_{1} w}=\frac{1}{M_{1}}=\frac{p-\frac{c}{2}}{p-v} \\
=\frac{\int_{0}^{Q_{s y m}^{*}} F(x) d x}{Q_{s y m}^{*}}
\end{gathered}
$$

$\lim _{w \rightarrow p^{-}} H(w)$ means suppliers can improve the wholesale price and the recycling price to make the order quantity of retailers increasing, but could not make the order quantity of retailer equal to the optimal-order quantity under centralized decision, namely the supplier cannot coordinate the supply chain through the buyback contract, but can promote the retailer's order quantity increasing.

Corollary 6 shows that although the supplier cannot coordinate the supply chain, but can encourage retailers to 
increase the order quantity according to the actual situation by taking advantage of the second optimal strategy.

\section{CONCLUSION}

This paper studies the optimal decision of retailer and supplier based on the shortage of market supply. Compared with the normal supply situation, it is found less optimal order quantity from the retailer; and that the retailer's optimal order quantity decreases with wholesale prices increasing, increases with the retail price and residual value increasing. The supplier can increase the or-der quantity of the retailer through the buyback contract, but cannot coordinate the supply chain through the buyback contract.

The following research can be further studied whether the other contracts can be coordinated the supply chain, and that what is the optimal decision when the supplier conceal the information of shortage to the retailer, and that the retailer's optimal decision under the capital constraints, and so on.

\section{ACKNOWLEDGMENT}

\section{Supported by the Huizhou University Project} (C512-0103)

\section{REFERENCE}

[1] HUANG Zhu-qing, DA Qing- li and ZHANG Qin, " A model of cooperative competition in the supply chain under the condition of shortage". The Journal of Quantitative \& Technical Economics, vol. 21,2004, (1), pp. 87-93.

[2] ZHANG Qin, DA Qing-li and SHEN Hou-cai, "EOQ Models based on stackelberg game in supply chain," Chinese Journal of Management Science, vol. 10, Jun. 2002, (3), pp. 38-42.

[3] LH Chen and FS Kang, "Coordination between vendor and buyer considering trade credit and items of imperfect quality," International Journal of Production Economics, vol. 123, Jan. 2010, pp. 52-61.

[4] W Hartanto, P Andrew and N Mohamed, "Evaluation of postponement in the soluble coffee supply chain: a case study," International Journal of Production Economics, vol. 131, May. 2011, pp. 355-364.

[5] Q Jing, PL Jia and Y Sheng, "Inventory and package postponement strategy". Procedia Engineering, vol. 15, 2011, (2), pp. 4687-4692.

[6] GANG Hao, TANG Xiao-wo and MU Yin-ping, "Operation and coordination of supply chain under delay in payment with a loss-averse retailer," Control and Decision, vol. 28, Jul. 2013, pp. 1023-1027.
[7] ET Anderson, G J Fitzsimons and D Simester, "Measuring and mitigating the costs of stockouts". Management Science, vol. 52, Nov. 2006, pp. 1751-1763.

[8] LIU Bin and CUI Wen-tian, "Supply coordination for perishable commodities with goodwill cost more than replenishing cost". Journal of Industrial Engineering / Engineering Management, vol. 23, Oct. 2009, pp. 150-152.

[9] Choi Tsan-Ming, Li Duan and Yan Hou-min, "Mean-variance analysis of a single supplier and retailer supply chain under a returns policy”. European Journal of Operational Research, vol. 184, Jan. 2008, pp. 356-376.

[10] J T acobson and K Roszbach, "Bank lending policy, credit scoring and value-at-risk". Journal of Banking \& Finance, vol. 27, Jan. 2003, (4), pp. 615-633.

[11] Wu J, W Yue and Y Yamamoto, "Risk analysis of a pay to delay capacity reservation contract," Optimization Methods and Software, vol. 21, Mar. 2006, pp. 635-651.

[12] D Kahneman and A Tversky, "Prospect theory: An analysis of decisions under risk," Econometrica, vol.47, Mar.1979, pp. 263-292.

[13] SUO Han-sheng and JIN Yi-hui, "Buy back policy under asymmetric information in two-stage supply chain". Computer Integrated Manufacturing Systems, vol. 9, Mar. 2003, pp. 746-749.

[14] XU Xiao-yan and WU San-ping, "Coordinating two-echelon supply chain with asymmetric information of manufacturing cost," Journal of Systems Engineering, vol. 24, Feb. 2009, (1), pp. 18-24.

[15] J Causen, $\mathrm{H}$ J ansen and $\mathrm{J}$ Larsen, "Disruption management ,"OPPMS Today, vol. 28, Sep.2001, pp. 40-43.

[16] YU Hui, CHEN Jian and YU Gang, "Managing whole-sale price contract in the supply chain under disruptions". Systems Engineering-Theory \& Practice, vol. 26, Aug. 2006, (8), pp. 33-41.

[17] YU Hui and CHEN Jian, "Response to the disruption of supply chain with price-depended demand," Systems Engineering-Theory \& Practice, vol. 27, Mar. 2007, pp. 36-41.

[18] WU Zhong-he, CHEN Hong, ZHAO Qian and WU Xiao-zhi, "Supply chain coordination with demand and purchase cost of retailers disruption, "Chinese Journal of Management Science, vol. 20, Feb. 2012, pp. 110-117.

[19] CAO Er-bao and LAI Ming-yong, "Research on coordination mechanism of supply chain with disruption when multiple retailers competition, "Chinese Journal of Management Science, vol. 17, Oct. 2009, pp. 53-60.

[20] QIN Yan-hua, CAO Xi-yu and SONG Lu-jun, "Supply chain coordination with asymmetric demand information under disruption". Operations Research and Management Science, vol. 21, Aug. 2012, pp. 60-64.

[21] ZHANG Ju-liang and CHEN Jian, "Vender manage inventory under disruption". Chinese Journal of Management Science, vol. 16, Oct. 2008, pp. 71-76. 